\title{
Protecting Dr. Smith While Treating the Chronic PAIN OF MRS. JONES: \\ Why The Indiana Medical LiCENSING BoARD SHOULD Pass GuIdelines for USING Controlled Substances FOR PAIN TREATMENT
}

\author{
Macon Jones*
}

"The end of law is not to abolish or restrain, but to preserve and enlarge freedom. For in all the states of created beings, capable of laws, where there is no law, there is no freedom."

-John Locke ${ }^{1}$

I. INTRODUCTION

II. BACKGROUND

III. THE CURRENT STATUS OF INTERESTED PARTIES FOR INDIANA'S POLICIES CONCERNING CONTROLLED SUBSTANCE PRESCRIBING FOR

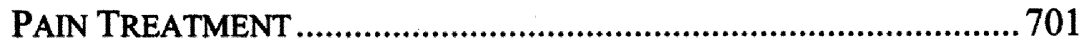

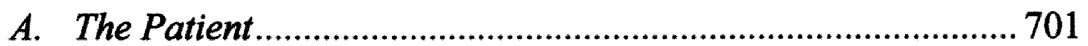

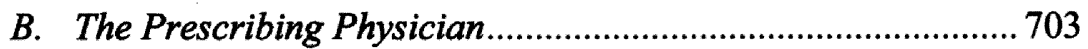

1. Duty to Treat Patient Pain ................................................ 703

2. Interest in Perpetuating Practice in Medicine ...................704

C. The Office of the Indiana Attorney General............................... 706

D. The Indiana Medical Licensing Board.................................... 708

IV. THE GUIDELINE SOLUTION.......................................................709

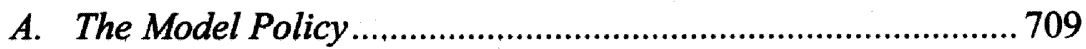

B. The Michigan Guideline ........................................................ 711

C. Indiana's Attempt to Promulgate a Rule for Using Controlled

Substances in a Pain Treatment Setting..................................... 713

D. How a Guideline Would Operate Under Indiana's Statutory Scheme

V. THE ROLE OF A GUIDELINE TO ACHIEVE AND BALANCE ALL INTEREST

A. A Guideline Will Clarify the Law and Create Case Evaluation

Criteria.

* J.D. Candidate, 2012, Indiana University Robert H. McKinney School of Law; B.A., 2005, University of North Florida.

1. John Locke, The Second Treatise of Civil Government Chap. VI, Sec. 57 (1690). 


\section{The Indiana Medical Licensing Board Members Are Not} Pain Management Specialists ........................................ 717

2. The Case of David and Charles Chube ............................. 718

B. Clear Standards Put Physicians on Notice as to Proper Prescribing Practices............................................................. 722

1. A Guideline Will Alleviate Fear of Regulatory Scrutiny... 722

2. A Clear Guide Will Enable Proper Defense..................... 723

C. The Patients Will Receive Better Treatment .......................... 725

VI. THE CASE AGAINST A GUIDELINE.............................................. 725

A. There is No Enforceability With a Guideline........................... 725

B. Restricts the Practice of Medicine ........................................ 728

C. Specific Standards Are Not Necessary to Achieve Physician

Discipline............................................................................. 729

D. Patient Concern of Required Documentation........................ 729

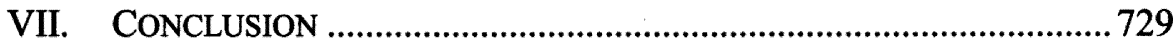

\section{INTRODUCTION}

A war is raging; it is one that includes all members of society: the indigent, wealthy, young, old, and all flavors of race, nationality, and gender. It is the war on prescription medication. According to the Drug Enforcement Administration ("DEA"), six million Americans currently abuse a prescription drug, which is more than abusers of heroin, cocaine, hallucinogens, and inhalants combined. ${ }^{2} 1.85$ million people are estimated to be dependent on or abusing schedule II controlled substances, also known as opioids. $^{3}$ In 2009, 1.2 million individuals were treated in an emergency department for conditions involving pharmaceutical drug use, which is a ninety-eight percent increase from $2004^{4}$ This increase is especially startling considering that emergency room treatment involving illicit drugs has remained virtually unchanged over the same period. ${ }^{5}$ In response, Federal and State governments have taken multiple steps to address this serious and growing problem. On September 25, 2010, the DEA held its first "National

2. Practitioner's Manual, DRUG ENFORCEMENT ADMIN. OFFICE OF DIVERSION CONTROL, http://www.deadiversion.usdoj.gov/pubs/manuals/pract/section1.htm (last visited Mar. 11, 2012).

3. Cynthia Gregorian, Addiction to painkillers hobbles more patients, STL TODAY (Oct. 27, 2010), http:/www.stltoday.com/lifestyles/health-med-fit/fitness/article_f6777202785b-5703-9319-17df8d32c29b.html. Schedule II controlled substances are beneficial and effective medications that also have a high potential for abuse and addiction, thus, their use is regulated. 21 U.S.C. $\S 812(\mathrm{~b})(2)(2011)$.

4. Abby Goodnough, Prescription Drug Abuse Sends More People to the Hospital, N.Y. TIMES, Jan. 5, 2011, http://www.nytimes.com/2011/01/06/health/06drugs.html? $\mathrm{r}=2$ \&ref=health.

5. Id. 
Prescription Drug Take Back Day" which allowed anyone to return unused prescription medication with no questions asked. ${ }^{6}$ This activity was motivated by the desire to reduce the amount of unused medication available for diversion. ${ }^{7}$ Further, in recent years the DEA has stepped up its investigations and prosecutions of physicians, especially those who prescribe OxyContin, a schedule II controlled substance and one of the most widely prescribed and abused opioids. ${ }^{8}$

Indiana has a particularly concerning controlled substance abuse problem. In the most recent Substance Abuse and Mental Health Services Administration ("SAMHSA") report, Indiana ranked among the highest in the country for non-medical pain reliever use in all age groups except ages twelve through seventeen. However, Indiana has also adopted measures to combat prescription drug abuse and diversion, including Indiana's controlled substance monitoring program ("INSPECT" program) created in $2006,{ }^{10}$ and the passage by the state legislature of the Prescription Drug Disposal Sites - House Bill 1121, ${ }^{11}$ which would allow individuals to return unused medications to their pharmacy for proper disposal. ${ }^{12}$ Also, in the past year the Office of the Indiana Attorney General has prosecuted numerous physicians who divert and improperly prescribe prescription drugs. ${ }^{13}$ Prescription drug abuse has become a crisis nationally and in Indiana and more safeguards are needed.

However, in developing additional safeguards by regulating access to prescription drugs, one must be careful not to unnecessarily restrict access from legitimate users. While prescription drugs are widely abused, they can also provide life altering relief from pain that cannot otherwise be treated. As a casualty in the war on prescription drug abuse, undertreated pain has quietly become a nationwide epidemic. ${ }^{14}$ Many factors contribute to under-

6. National Take Back Initiative, DRUG ENFORCE. ADMIN. OFFICE OF DIVERSION CONTROL, http://www.deadiversion.usdoj.gov/drug_disposal/takeback/ (last visited Jan. 17, 2011).

7. Id.

8. Ronald T. Libby, Treating Doctors as Drug Dealers: The DEA's War on Prescription Painkillers, 545 PoL. ANALYSIS 1, 1 (2005), available at http://www.cato.org/pubs/pas/ pa545.pdf.

9. Substance Abuse \& Mental Health Servs. Admin., U.S. Dep't of Health \&

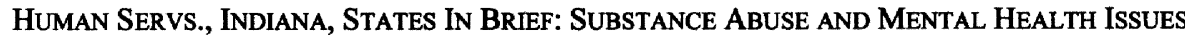
AT-A-GLANCE, A SHORT REPORT FROM THE OFFICE OF APPLIED STUDIES (2009), available at http://www.samhsa.gov/statesinbrief/2009/INDIANA_508.pdf.

10. IND. CODE $§ 35-48-7-10.1$ (2010).

11. H.B. 1121, 117th Gen. Assemb., 1st Reg. Sess. (Ind. 2011), available at $\mathrm{http}: / / \mathrm{www}$.in.gov/legislative/bills/2011/PDF/HB/HB1121.2.pdf.

12. Press Release, Ind. Att'y Gen., AG, legislators support bill for safe disposal of prescription drugs (Jan. 10, 2011), http://www.in.gov/attorneygeneral/2369.htm.

13. See Findings of Fact, Ultimate Findings of Fact, and Order, In the Matter of the License of Beverly P. Edwards, 2009 MLB 0024 (Ind. Med. Licensing Bd., Mar. 30, 2010) [hereinafter Edwards, Findings of Fact and Order].

14. Ben A. Rich, A Prescription for the Pain: The Emerging Standard of Care for 
treated pain, but one important influence is physician concern about both law enforcement and regulatory scrutiny: physicians are reluctant to prescribe adequate amounts of controlled substances for pain because of the potential for investigation by the DEA and the state medical licensing board. $^{15}$ As a result, patients indirectly suffer from amped-up efforts to control prescription drug abuse by focusing on physician prescribing practices. Therefore, regulations placed on prescription drugs must consider all interests implicated and fashion a strategy that serves to address prescription drug abuse while allowing doctors to adequately treat the pain of their patients.

This Note will argue that the Indiana Medical Licensing Board should pass guidelines for the use of controlled substances for the treatment of pain. Guidelines would address the ever-increasing concern over prescription drug abuse by creating a standard that would allow physicians to prescribe proper amounts of controlled substances for pain treatment without fear of investigation. In addition, guidelines would provide a method for the Office of the Indiana Attorney General to assess and take appropriate action against physicians who use medicine as a pretext for diversion and ultimately are not prescribing for legitimate medical purposes and give the Indiana Medical Licensing Board an evaluation tool to properly scrutinize physician prescribing practices. This Note will consider the interests implicated by the adoption of guidelines for controlled substances in the context of pain treatment including patients, physicians, the Office of the Indiana Attorney General, the Indiana Medical Licensing Board, and Indiana citizens generally. Further, this Note will consider several disciplinary actions and criminal convictions of Indiana physicians who have been disciplined for their prescribing practices and compare Indiana law and regulations with the efforts of Michigan in the area of pain management using controlled substances. This Note concludes that guidelines adopted by the Indiana Medical Licensing Board will serve all interests involved and will ameliorate prescription drug abuse and diversion while alleviating undertreated pain and physician fear in Indiana.

Pain Management, 26 WM. MrTCHELL L. REv. 1, 2 (2000); see also David B. Resnik et al., The Undertreatment of Pain: Scientific, Clinical, Cultural, and Philosophical Factors, 4 MED. HEALTH CARE PHIL. 277 (2001) (arguing that undertreatment of pain is due to a faulty philosophical approach to pain management); Steven E. Stark, Bio-Ethics and Physician Liability: The Liability Effect of Developing Pain Management Standards, 14 ST. THOMAS L. REV. 601, 638 (2002) ("There is an increasing perceived inability of the medical profession to deliver adequate pain management and adequate palliation of pain to those with acute or chronic illness and to those with terminal illness."); but see Norman Miller et al., Controlled Substance Laws: Are They Meeting the Health Needs of the Public?, 7 Mich. ST. J. MED. \& LAw 81, 83 (2003) ("In the past ten years or so, a growing mood of entitlement of absolute pain relief has obscured decades of hard earned wisdom that narcotic medications contain inherent 'pain' from their pharmacological effects, and addictive properties that are not negated by the presence of pain in an individual.").

15. Aaron Gilson, et al., Improving State Medical Board Policies: Influence of a Mod$e l, 31$ J.L. MED. \& ETHICS 119, 119 (2003). 


\section{BACKGROUND}

In Indiana, there are two agencies that are involved in regulating the professional practice of physicians. The Office of the Indiana Attorney General ("AG") is the investigative and prosecutorial arm, ${ }^{16}$ and the Indiana Medical Licensing Board ("Board") is the entity that licenses and disciplines physician practice. ${ }^{17}$ Any action conducted by these agencies only relates to the physician's license and ability to legally practice medicine in Indiana. ${ }^{18}$ No criminal penalties are imposed, although a finding of unprofessional conduct allows for discipline on the physician's license. ${ }^{19}$ The process begins when the AG receives allegations of improper physician conduct, which can come from a variety of sources, including patient complaints, other state disciplinary committees, media outlets, and the Board itself. ${ }^{20}$

After receiving this information, the AG conducts an investigation of the alleged conduct, including a response to the allegations by the physician in question. $^{21}$ After a thorough review of the information available, the AG makes a recommendation of the action to be taken and submits it to a member of the Board for their comments and impressions. ${ }^{22}$ Based on the Board member's comments and in-house attorney recommendations, the AG will then decide whether to file a formal administrative complaint against the physician or close the matter altogether. ${ }^{23}$ In the event that the AG decides to take action against the physician's license, they will file a formal administrative complaint with the Board. ${ }^{24}$ The complaint will allege that the physician has committed a licensing violation under Indiana Code ("IC") section $25-1-9-4,{ }^{25}$ which is commonly referred to as the Licensing Charging Statute. ${ }^{26}$ The physician will then either decide to settle with the AG, subject to the Board's approval, or defend the allegations in an administrative hearing before the Board. ${ }^{27}$ The AG serves as the prosecution in the

16. IND. CODE § 25-1-7-7 (2010).

17. IND. CODE $\S 25-22.5-2-7$ (2010). The Board is a subset of the Indiana Professional Licensing Agency ("IPLA") which is the official agency charged with regulating all professional practices in Indiana under IND. CODE § 25-1-5-3 (2010).

18. IND. CODE \& 25-22.5-2-7 (2010).

19. IND. CODE $\S 25-1-9-4(2010)$.

20. See Consumer Complaints, OfFice OF THE IND. ATT'Y GENERAL, http://www.in. gov/attorneygeneral/2434.htm (last visited Mar. 11, 2012).

21. Interview with Gabrielle Owens, Section Chief, Licensing Enforcement and Homeowner Protection Unit, Office of the Ind. Att'y Gen., in Indianapolis, Ind. (Feb. 28, 2011) (on file with author).

22. $I d$.

23. Id.

24. Id.

25. Id.

26. Id.

27. Id.; see also Stipulated Findings of Fact, Stipulated Conclusions of Law, Ultimate Conclusions of Law, and Order, In the Matter of the License of Michael A. Punnett, 2009 
hearings. $^{28}$

The hearing takes place before the Board, which is comprised of up to seven members appointed by the Governor. ${ }^{29}$ Six Board members are physicians from all over Indiana, and at least one physician must be a doctor of osteopathy while the other five must be doctors of medicine. ${ }^{30}$ The last member is a consumer member that can be any citizen of Indiana and serves as a representative of all Indiana consumers. ${ }^{31}$ The Board is charged with regulating physician practice in Indiana and protecting consumers from fraud and abuse by licensed physicians. ${ }^{32}$ The Board primarily consists of physicians because it is believed that they are in the best position to evaluate medical practice. ${ }^{33}$ As such, the Board promulgates rules for the practice of medicine, approves physicians for licensure, and disciplines physicians who violate Indiana law and the professional standards for the practice of medicine set by the Board. ${ }^{34}$ The Board may discipline the physician's license by issuing a letter of public reprimand; by taking action on the physician's license, including revocation, suspension, or probation; by imposing fines up to $\$ 1,000$ for each violation; or by a combination of the penalties listed. ${ }^{35}$

In order to impose disciplinary action on a physician's license, the Board must find that the physician violated one of the thirteen provisions found under IC 25-1-9-4 ("Charging Statute"). 36 Such provisions prohibit physician-patient sexual relations, prescription drug diversion, the use of material deception to obtain a license to practice, failure to keep abreast of current professional theory or practice, and others. ${ }^{37}$ Moreover, the Board is authorized to promulgate additional rules, ${ }^{38}$ a violation of which would constitute varying violations of the charging statute. ${ }^{39}$ These rules are tailored to address "Standards of Professional Conduct and Competent Practice of Medicine" and are codified in the Indiana Administrative Code ("IAC") title 844, section 5. ${ }^{40}$ For example, IC 25-1-9-4(a)(4)(B) requires

MLB 0032 (Ind. Med. Licensing Bd., Jun. 30, 2010).

28. IND. CODE § 25-1-7-2 (2010).

29. IND. CODE $\S 25-22.5-2-1(2010)$.

30. IND. CODE § 25-22.5-2-1(1) (2010); IND. CODE § 25-22.5-2-1(2) (2010).

31. IND. CODE § 25-22.5-2-1(3) (2010).

32. IND. CODE $§ 25-22.5-2-7$ (2010).

33. See generally IND. CODE § 25-22.5-2 (2010).

34. IND. CODE $§ 25-22.5-2-7(2010)$.

35. IND. CODE § 25-1-9-9 (2010).

36. IND. CODE $\S 25-1-9-9$ (2010). This statute recognizes two other specific instances in which the Board has authority impose discipline, which are Indiana Code section 25-1-96.8, "Practitioner guidelines before prescribing stimulant medication for a child for treatment of certain disorders," and Indiana Code section 25-1-9-6.9, "Failing to provide or providing false information to agency." However, these statutes are rarely invoked and the discipline in the scope of this Note is covered under the charging statute.

37. IND. CODE § 25-1-9-4 (2010).

38. IND. CODE $§ 25-22.5-2-7(2010)$.

39. See IND. CODE § 25-1-9-4 (2010).

40. 844 IND. ADMIN. CODE 5 (2010). 
physicians to "keep abreast of current professional theory and practice,"41 and a violation of 844 IAC 5-3-3, which disallows treatment based on online questionnaires, ${ }^{42}$ would invoke the charging statute causing the $A G$ complaint to charge the physician with a violation of IC 25-1-9-4(a)(4)(B) to wit, 844 IAC 5-3-3, because the Board must prosecute for a violation of the charging statute. ${ }^{43}$ While some of the provisions appear to be criminal in nature, all provisions under the charging statute are licensing violations subject to discipline by the Board against the physician's license. ${ }^{44}$

\section{THE CURRENT STATUS OF INTERESTED PARTIES FOR INDIANA'S Policies CONCERNING CONTROLLED SUBSTANCE PRESCRIBING For PAIN TREATMENT}

When statutes, regulations, or policy statements are adopted, passed, and implemented, unintended parties may be affected for good or ill. Especially in the area of health law, where life-saving work is being performed, a careful examination of all implicated parties is necessary to properly balance the interests and devise an appropriate strategy for accomplishing the desired goal. For the purposes of this Note, the interested parties are patients, prescribing physicians, the $\mathrm{AG}$, the Board, and the general public. Patients receive pain treatment through appropriate physician prescribing; the physicians prescribe and earn a living through their practice; the AG is empowered by the state to protect the health and welfare of Indiana citizens by bringing complaints against licensed Indiana physicians; the Board is empowered to protect the health and welfare of Indiana citizens by disciplining the license of Indiana physicians; and, the Indiana public has an interest in protection from prescription drug abuse.

\section{A. The Patient}

In the context of using controlled substances for pain treatment, the patient's interest is receiving safe and effective pain treatment and relief from suffering. ${ }^{45}$ Patients are the ones who are experiencing pain and are in need of help. Generally, three types of pain are recognized: acute, chronic

41. IND. CODE § 25-1-9-4(a)(4)(B) (2010).

42. 844 IND. ADMIN. CODE 5-3-3 (2010).

43. Edwards, Findings of Fact and Order, supra note 13.

44. For example, Indiana Code section 25-1-9-4(a)(8)(A) which states "a practitioner has diverted: a legend drug (as defined in IC 16-18-2-199)" is a licensing violation subject to discipline by the Board under Indiana Code section 25-1-9-9, but would also be a violation of Indiana Code section 35-48-4-2, "Dealing in a schedule I, II, or III controlled substance," and subject to criminal prosecution as a Class B felony.

45. Rich, supra note 14, at 31 ("The suffering at issue is that of the patient with whom he or she has entered into a professional relationship."). 
non-cancer pain, and chronic cancer related pain. ${ }^{46}$ This Note will address chronic non-cancer pain because such pain is outside the scope of palliative care and is frequently targeted by guidelines and provisions to prevent abuse and addiction.

"Chronic non-cancer pain is associated with significant economic, societal, and health impact." 48 On the economic front, the cost of uncontrolled non-cancer chronic pain is extreme. In 1998 it was estimated that total expenditures for back pain was $\$ 90.7$ billion and, on average, people with back pain cost health care insurance providers sixty percent more than those without back pain. 49 "It was estimated [in 1998] that the cost of health care for patients with chronic pain might exceed the combined cost of treating patients with coronary artery disease, cancer, and AIDS."50 From a societal perspective, undertreated pain directly impacts a patient's quality of life. $^{51}$ It is not easy living with unremitted moderate to severe pain, and, in certain cases, excessive pain can lead to depression and even suicide. $^{52}$ Undertreated pain has been equated and compared to inflicting pain on the suffering patient and, as such, has implicated ethical and judicial/licensing liability concerns. It is argued that " $[\mathrm{h}]$ ealth care providers also should not inflict unnecessary pain and suffering .... [A]llowing a patient to experience unnecessary pain and suffering of any form is substandard and unethical medical practice regardless of the nature of the patient's condition or the goals of medical intervention."53

In light of the fact that unrelieved pain is an undue burden on patients, controlled substances in the morphine class known as opioids can be used as safe and effective ways to treat patient pain, especially when the pain is severe. ${ }^{54}$ Many physicians argue that there is no ceiling on how much one

46. See OR. Bd. Of MED. Exam'RS, InTractable PAIn ANd PaIn Management: BME Statement of Philosophy ON PAIN MANAGEMENT (2004), available at http://www.pain policy.wisc.edu/domestic/states/OR/ormbgd2.htm.

47. Renata Ferrari, Michela Capraro \& Marco Visentin, Risk Factors in Opioid Treatment of Chronic Non-Cancer Pain: A Multidisciplinary Assessment, in PAIN MANAGEMENT CURRENT ISSUES AND OPINIONS 419, 450 (Gabor B. Racz and Carl E. Noe, eds., 2012), available at http://cdn.intechopen.com/pdfs/26149/InTech-Risk factors in_opioid treatment of chronic non_cancer_pain_a multidisciplinary_assessment.pdf.

48. Laxmaiah Manchikanti, Prescription Drug Abuse: What is Being Done to Address This New Drug Epidemic? Testimony Before the Subcommittee on Criminal Justice, Drug Policy and Human Resources, 9 PAIN PHYSICIAN 287, 288 (2006).

49. Id.

50. Id.; see also S.H. Hernandez \& L.S. Nelson, Prescription Drug Abuse: Insight Into the Epidemic, 88 Clinical Pharmacology \& Therapeutics 307, 310 (2010) (discussing the monetary costs of pain treatment).

51. Manchikanti, supra note 47 at 288.

52. See Kate Scott et al., Chronic Physical Conditions and Their Association With First Onset of Suicidal Behavior in the World Mental Health Surveys, 72 Psychosomatic MED. 712 (2010).

53. Rich, supra note 14 , at 3.

54. Amy J. Dilcher, Damned If They Do, Damned If They Don't: The Need for a Comprehensive Public Policy to Address the Inadequate Management of Pain, 13 ANN. HEALTH 
may ingest to treat pain asserting that "[a]s long as the dose is [started] low and increased gradually, large doses [may] be taken [and are] limited only by adverse [side] effects . . . . [O]pioids do not cause damage to major organs. The correct amount, [physicians] argue, is what reduces or eliminates the patient's pain without unacceptable side effects." ${ }^{\text {"55 }}$ Therefore, any restriction or regulation on pain patients' access to opioids impacts the patients' ability to receive powerful solutions to their chronic and potentially debilitating pain.

\section{B. The Prescribing Physician}

The physicians implicated in this Note are those who prescribe controlled substances to treat their patients' pain. These physicians have a twofold interest: their duty to their patients and their interest in perpetuating their practice in medicine.

\section{Duty to Treat Patient Pain}

The physician's first interest is in maintaining his duty to properly treat his patients and, in cases of pain management, adequately treating pain. $^{56}$

When conducting an inquiry into the duties of a physician, the first step (and sometimes last resort) is to consult the Hippocratic Oath. However, . . . the fact that the Oath makes no specific reference to the relief of suffering should not be dispositive of the issue of the physician's duty in that regard. ${ }^{57}$

Philosopher Rem Edwards argues that "there is a broadly based humanistic ethics which applies to the domain of medical care which gives patients a strong prima facie right to freedom from unnecessary pain. ${ }^{, 58}$ Further, the World Health Organization ("WHO") has recognized pain treatment as a basic human right and has determined that pain treatment is one of the most underestimated health care problems in the world. ${ }^{59}$ It is argued that not relieving pain is almost akin to willfully inflicting it, and "[t]he willful infliction of pain is torture, which is foreclosed to the gov-

L. $81,82(2003)$.

55. Diane E. Hoffmann, Treating Pain v. Reducing Drug Diversion and Abuse: Recalibrating the Balance in Our Drug Control Laws and Policies, 1 ST. LoUIS U. J. HEALTH L. \& POL'Y 231, 270 (2008).

56. Rich, supra note 14 , at 2.

57. Id. at 32-33.

58. Id. at 33 .

59. World Health Organization supports global effort to relieve chronic pain, WORLD HEALTH ORG., Oct. 11, 2004, http://www.who.int/mediacentre/news/releases/2004/pr70/en/. 
ernment by the Eighth Amendment to the U.S. Constitution, even in the punishment of convicted criminals as "cruel and unusual.",60

While the issue of a patient's right to be free from pain is an ethical duty imposed on physicians in Indiana, the Oregon medical board has disciplined a physician for under-treated pain and a California jury awarded $\$ 1.5$ million to the family of a man whose physician failed to provide proper amounts of pain medication before he died of cancer. ${ }^{61}$ While there is concern that patients can become addicted to powerful opioids prescribed for pain relief, ${ }^{62}$ especially when a patient has a history of substance abuse, some states have decided that such concerns are no excuse to allow patients to suffer. Whether imposed ethically or as a standard of practice, physicians have a duty to adequately address the pain of their patients or at least refer patients for such treatment. ${ }^{63}$

\section{Interest in Perpetuating Practice in Medicine}

The physician not only has an interest in relieving his patient's pain on legal and moral grounds, but also has a corresponding interest in maintaining his livelihood. Discipline for inappropriate prescribing can lead to the revocation of the physician's license or criminal penalties, thus ending the physician's ability to practice medicine and potentially earn a living. ${ }^{64}$ The physician must preserve his ability to work. He has a duty to his patients, but maybe a greater one of self-preservation and the continued validity of his license.

Because of the physician's interest to maintain an unrestricted license, restrictions or lack thereof on opioid prescribing is of major concern to prescribing physicians who are attempting to treat patient pain. Considering the war on prescription drug abuse, physicians are often hesitant to aggressively treat patient pain with opioid use out of anticipation that such practices will draw investigation by state and federal agencies. ${ }^{65}$

60. Rich, supra note 14 , at 49.

61. For the dying and others in pain, doctors rethinking relief, PROVIDENCE J. BULlETIN, Sep. 30, 2001, available at 2001 WLNR 4498410.

62. See Mich. DeP't of CMTy. Health, SuRvey of Physicians 15-16 (2009), available at $\mathrm{http}: / / \mathrm{www} . \mathrm{michigan}$.gov/documents/healthcareworkforcecenter/2009Physicians SurveyFINALREPORT 308082 7.pdf.

63. Rich, supra note $1 \overline{4}$, at 34-35 (2000) ("American doctors regularly refuse to prescribe effective doses of narcotic painkillers to dying patients on the grounds that the patients might become addicted. The treatment of cancer pain, clearly, is still not based solely on scientific fact but draws on ignorance, fear, prejudice, and on an invisible, unacknowledged moral code expressing half-baked notions about the evil of drugs and the duty to bear affliction.").

64. Edwards, Findings of Fact and Order, supra note 13; Beverly P. Edwards, 75 Fed. Reg. 157, 49991-92 (D.E.A. Jul. 30, 2010), available at http://www.gpo.gov/fdsys/pkg/FR2010-08-16/pdf/2010-20193.pdf.

65. Rich, supra note 14, at 43 (stating that physicians often have "opiophobia [which] denotes an unreasonable fear of and resultant reluctance to prescribe, administer, or receive 
[F] ears over the prospect of legal entanglement and potential sanctions may influence doctors to alter their practices in undesirable ways . . . Doctors also fear being subjected to government inquiry or investigation. The costs of the inquiry or investigation include financial costs, disruption of the practice, damage to reputation, resultant ostracism or termination of necessary business relationships, stress, shame, and other losses that are quite significant. ${ }^{66}$

In many cases, physicians claim that "bad laws" in the regulatory and legislative system force them to provide futile or poor care because they are more concerned with following the law than adequately treating their patients. 67

The concern here is that unclear or nonexistent law deters physicians from providing proper treatment for their patient's pain because physicians are either scared of government investigation or concerned about following the letter of the law, all to the detriment of the patient. Numerous studies have connected fear of regulatory scrutiny and ambiguous standards directly to incomplete pain treatment. ${ }^{68}$ In a 1991 survey of physicians at the American Pain Society, forty percent of the physicians reported that fear of regulatory scrutiny, and not medical considerations, caused them to prescribe fewer opioids for pain treatment. ${ }^{69}$ In a more startling 1993 California survey, sixty-nine percent of physicians stated they felt pain treatment was more conservative because of fear of government investigation, and one-third actually believed their patients were suffering from untreated pain. $^{70}$ In Indiana, there are no statutes, regulations, or standards of practice specifically tailored to address the use of controlled substances for pain treatment. Indiana's "bad law" is the lack of standards by which physicians are evaluated, thus directly contributing to physician fear of regulatory scrutiny by promoting ambiguity about the practice of pain management and indirectly preventing Indiana citizens from receiving proper pain treat-

opioid analgesics, even for the relief of severe pain which is unresponsive to other available pain management strategies. While the phenomenon of opiophobia is not unique to American culture, the openly declared war on drugs by American politicians and bureaucrats has produced a particularly virulent form of it in this country"); see also Amy J. Dilcher, Damned If They Do, Damned If They Don't: The Need for a Comprehensive Public Policy to Address the Inadequate Management of Pain, 13 ANN. HEALTH L. 81, 113-15 (2004).

66. Sandra H. Johnson, Regulating Physician Behavior: Taking Doctors' "Bad Law" Claims Seriously, 53 ST. Louis UNIV. L.J. 973, 1024, 1029 (2009).

67. Id. at 974.

68. Diane E. Hoffmann \& Anita J. Tarzian, Achieving the Right Balance in Oversight of Physician Opioid Prescribing for Pain: The Role of State Medical Boards, 31 J.L. MED. \& ETHICS 21, 23 (2003).

69. Id.

70. Id. 
ment. ${ }^{71}$ "Until the boundaries between [law and pain treatment] are clarified, physicians will remain reticent to aggressively treat severe intractable pain, and patients will continue to suffer as they struggle to find relief."

\section{The Office of the Indiana Attorney General}

As the AG investigates and prosecutes physicians who commit licensing violations, any new or additional regulation will affect that responsibility, thus impacting its ability to protect Indiana citizens. In the context of pain management, there are currently no regulations or standards of practice promulgated by the Board, therefore requiring the AG to seek general evidence that a physician's prescribing practice is harmful to the public. ${ }^{73}$

When prosecuting physicians for prescribing practices under the charging statute, the AG can prosecute for "failure to keep abreast of current professional theory or practice, ${ }^{, 74}$ diverting a controlled substance, ${ }^{75}$ or "except as otherwise provided by law, has knowingly prescribed, sold, or administered any drug classified as a narcotic, addicting, or dangerous drug to a habitue or addict." requires physicians to adhere to current professional theory and practice, is essentially the "Catch All" provision used to show that physicians have used substandard care in their practice. However, because of the general language used, the Catch All statute must be supplemented by some other source defining the actual conduct that is not professional theory or practice. Generally, violations of the provisions in 844 IAC 5, which contains the Standards of Professional Conduct and Competent Practice of Medicine adopted by the Board, or other Indiana medical statutes are used to invoke a violation of the Catch All statute. However, neither 844 IAC 5 nor any other Indiana provision addresses prescribing practices for pain treatment, and the AG is left to resort to organizational standards, common knowledge, or expert testimony. ${ }^{77}$

In 2010, the AG successfully prosecuted several high profile cases involving prescribing practices, including revocations and fines against the

71. This Note recognizes that there are multiple factors contributing to physicians not adequately treating pain, but the burden is on the Board to take steps to get patients relief and fear of regulatory scrutiny is something they can directly address. See FED'N. OF STATE MED. BdS. OF THE U.S., INC., MODEL POLICY FOR THE USE OF CONTROLled SUBSTANCES FOR THE TREaTMENT OF PAIN (2004), available at http://www.fsmb.org/pdf/2004_grpol_Con trolled_Substances.pdf [hereinafter MODEL PoLICY] (discussing multiple barriers in pain management including fear of regulatory scrutiny).

72. Shannan W. Leelyn, Failures in Pain Management: The Collision of Law and Medicine, 27 T. JEFFERSON L. REV. 133, 156 (2004).

73. See 844 IND. ADMIN. CODE 5-2-5 (2010).

74. IND. CODE § 25-1-9-4(a)(4)(B) (2010).

75. IND. CODE § 25-1-9-4(a)(9) (2010).

76. Id.

77. See 844 Ind. AdMIN. Code 5-2-5 (2010). 
licenses of Dr. Beverly Edwards, Dr. Kara Benson-Rink, and Dr. Philip Foley. ${ }^{78}$ Dr. Edwards was disciplined under the Catch All statute because she prescribed controlled substances to thousands of patients across the country, in violation of 844 IAC 5-3, which prohibits internet prescriptions unless the physician physically saw the patient. ${ }^{79}$ Dr. Foley was charged under the same statute, but he had written over 96,000 prescriptions over a three-year period, averaging 1.4 prescriptions per minute, and 9 of his patients died from prescription drug overdose. ${ }^{80}$ Further, Dr. Kara Benson-Rink was successfully prosecuted under the Catch All statute for prescribing Vicodin to her husband and a friend without keeping any medical records in violation of IC 16-39-7-1 and under an expired DEA registration. ${ }^{81}$ In each of these cases, it was clear the physician had prescribed for purposes other than those supported by legitimate medical reasons or in direct violation of a specific statute or regulation, thus invoking the Catch All statute and posing little difficulty for the AG to secure the discipline on their licenses.

Under the current statutory format, the AG's interest in protecting Indiana citizens is only served when physicians violate the law in obvious and flagrant ways. However, the interest is not met when physicians keep some form of medical chart, do not prescribe over the Internet, or do not prescribe tens of thousands of opioids every month. In more tempered cases where physicians are careless or purposely prescribe for non-medical reasons, the AG lacks adequate tools with which to prosecute. If a physician is purposely over-prescribing, but maintains semi-proper charts and uses medicine or pain management as a pretext for diversion, the AG can do little under the current statutory scheme. Further, where a physician is careless or too trusting of his patients, the AG has a tremendous burden to show the physician has failed to keep abreast of current theory or practice, especially in an area where addicted patients are unlikely to report such practices. That is because the AG has no standard of practice to support a charge where the physician has ad hoc charts. In such instances, the AG can file a complaint and hope the physician will settle, but, while that might succeed in the latter case, it is unlikely when the physician uses medicine as a pretext for diversion. While the AG has statutory and regulatory backing to prosecute obnoxious cases and specific violations, those whose prescribing practices fall

78. Findings of Fact, Conclusions of Law, and Order, In the Matter of the License of Philip D. Foley, 2009 MLB 0031 (Ind. Med. Licensing Bd., Apr. 30, 2010) [hereinafter Foley, Findings of Fact and Order]; Edwards, Findings of Fact and Order, supra note 13; Findings of Fact, Ultimate Findings of Fact, and Order, In the Matter of the License of Kara Benson-Rink, 2009 MLB 0035 (Ind. Med. Licensing Bd., Apr. 30, 2010) [hereinafter Benson-Rink, Findings of Fact and Order].

79. Edwards, Findings of Fact and Order, supra note 13.

80. Foley, Findings of Fact and Order, supra note 77; Middletown doctor accused of killing patients with drugs, THE HERALD BULLETIN, Oct. 19, 2009, http://heraldbulletin.com/ breakingnews/x546199485/Middletown-doctor-accused-of-killing-patients-with-drugs.

81. Benson-Rink, Findings of Fact and Order, supra note 77. 
on the borderline pose a much more difficult, if not impossible, challenge.

\section{The Indiana Medical Licensing Board}

When the AG prosecutes unlawful physician behavior, the Board is the judge, jury, and rule maker. It presides over cases filed by the AG against licensed physicians and determines discipline with an interest and duty to protect the health and welfare of Indiana citizens. ${ }^{82}$ That interest is more pronounced considering the war on prescription drug abuse, and the fact that "[t]he largest group of prescription drug abusers is comprised of individuals who abuse opioids." 83 Empowered by Indiana Code section 2522.5-2-7(a)(8), the Board shall "[a]dopt rules establishing standards for the competent practice of medicine, osteopathic medicine, or any other form of practice regulated by a limited license or permit issued under this article." 84 Therefore, the Board is the gatekeeper as to what rules physicians will abide by in Indiana and has the most direct impact on what rules physicians will follow in their prescribing practices.

In its role as judge and jury, the Board hears the AG's complaints, evaluates physician conduct, and determines if a licensing violation has occurred under the appropriate statutory and regulatory provisions. ${ }^{85}$ Because there are currently no regulatory policies creating standards for using controlled substances for pain treatment, ${ }^{86}$ the Board faces the same issues as the AG in determining whether physician conduct is appropriate. While some cases exhibit clear violations by their magnitude or specificity, activities that toe the line and in the gray areas are difficult to evaluate. Because the Board is primarily comprised of licensed physicians, they are the most capable of determining whether a physician's prescribing practice is proper. ${ }^{87}$ However, Board members are not necessarily pain management spe-

82. IND. CODE $\S 25-22.5-2$ (2010); see also Stark, supra note 14, at 607-08 (outlining Florida's similar method of regulating physician behavior).

83. Manchikanti, supra note 47, at 290; see also Norman Miller et al., Controlled Substance Laws: Are They Meeting the Health Needs of the Public?, 7 MicH. ST. U. J. MED. \& L. 81, 94-98 (2003) (discussing high opioid abuse in the United States).

84. IND. CODE $\S 25-22.5-2-7$ (a)(8) (2010).

85. IND. CODE $§ 25-22.5$; see also Rich, supra note 14 , at 48 (discussing the customary procedures of state medical boards and its interactions with federal agencies).

86. It is recognized that Indiana does have some narrowly tailored provisions such as the Indiana Uniform Controlled Substances Act of 1973, IND. CoDE § 35-48 (2010), 844 IND. ADMIN. CODE 5-2-20 (2010) (Schedule II controlled substances for weight reduction), and 844 IND. ADMIN. CoDE 5-3-2 (2010) (Evaluation of the patient for internet purposes). However, the scope of this Note covers prescribing controlled substances for pain treatment and Indiana currently does not have any such statute or regulation.

87. As of April 2011, the current Board members are Stephen Huddleston, J.D. (consumer member), Bharat H. Barai, M.D. (hematology and oncology), Donald Vennekotter, M.D. (pediatric and general surgery), Worthe Holt, Jr., M.D. (family practice), Robert Allen, M.D. (urology), Lynda Smirz, M.D. (obstetrics and gynecology), and Kirk Masten, D.O. (anesthesiology). List Of Medical Licensing Board Members As of April 2011, IND. Prof'L 
cialists, and because they are the governor's appointees for finite terms subject to reappointment, they are subject to pressure from the legislature and the public to protect Indiana from unlawful physician practices. ${ }^{88}$ This pressure is heightened by the fact that Indiana is experiencing a crisis in prescription drug abuse and the Board, unlike the AG, has the authority and arguably the duty to have appropriate standards by which physicians prescribe opioids. Because there are no officially adopted standards of practice when prescribing controlled substances for pain, the Board is left to look to other sources to determine whether the physician practice is proper.

\section{THE GUIDELINE SOLU,TION}

After review of the interests implicated, it is evident that steps need to be taken to address patient pain treatment, physician prescribing practices, and concern about regulatory scrutiny. In addition, the AG's ability to prosecute and the Board's ability to evaluate physicians' prescribing practices should be examined. The solution is to implement guidelines that clearly establish a standard of practice for physicians who are prescribing medication to treat pain, but in doing so, retain the flexibility to adjust with changes in acceptable medical practices while providing an enforcement mechanism to hold physicians accountable.

\section{A. The Model Policy}

In 1997, the Federation of State Medical Boards ("FSMB") developed guidelines for the use of controlled substances for the treatment of pain. ${ }^{89}$ The guidelines were established in an effort to encourage state medical boards to have a consistent approach to pain treatment when dealing with controlled substances and to provide a standard that would help ensure proper pain treatment. ${ }^{90}$ Since its initial creation, the guidelines were revised in 2004 and have been titled "Model Policy for the Use of Controlled Substances for the Treatment of Pain" ("Model Policy"). "91 This document has been widely distributed and has been endorsed by the American Academy of Pain Medicine, the DEA, the American Pain Society, the National Association of State Controlled Substances Authorities, and the National Association of Attorneys General. ${ }^{92}$ The Model Policy is comprised of

LICENSING AGENCY, http://www.in.gov/pla/2485.htm.

88. See Discipline by state medical boards creates 'domino effect,' ACOG TODAY (Am. Cong. of Obstetricians and Gynecologists, D.C.), May/June 2005, at 14, available at http://www.acog.org/ /media/ACOG\%20Today/acogToday0505.pdf?dmc=1\&ts=20120411 T1551018826.

89. MODEL POLICY, supra note 71.

90. Id. at 2.

91. Id.

92. Id. at 1 
three sections, including the Preamble, Guidelines, and Definitions. ${ }^{93}$ The Preamble states the policy considerations for the Model Policy; the Guidelines reflect the actual actions physicians should take in treating patients with opioids; and, definitions simply define the medical terms used in the document. $^{94}$ In addition, pain medicine specialist Dr. Scott Fishman has written a guide that fleshes out the Model Policy and explains how to implement it in daily medical practice. ${ }^{95}$ The purpose of the policy is to encourage proper pain treatment in a time when undertreated pain is becoming a serious problem by outlining practices that are in compliance with federal and state law. 96

The Model Policy is designed to communicate certain messages to licensees: that the state medical board views pain management to be important and integral to the practice of medicine; that opioid analgesics may be necessary for the relief of pain; that the use of opioids for other than legitimate medical purposes poses a threat to the individual and society; that physicians have a responsibility to minimize the potential for the abuse and diversion of controlled substances; and that physicians will not be sanctioned solely for prescribing opioid analgesics for legitimate medical purposes. This policy is not meant to constrain or dictate medical decision-making. ${ }^{97}$

Those messages are shared by each state medical boards that have adopted the Model Policy or some variation. Arguably, the Board has a similar attitude. However, without something published or recorded, such sentiment likely has little meaning or force with the physician community. Throughout the United States, forty-nine of fifty-one jurisdictions, including Washington D.C., have adopted some standard for the use of controlled substances for the treatment of pain through legislation, regulations, or regulatory policy statements. ${ }^{98}$ Many of the states with some type of regulatory policy have utilized either the FSMB's Model Guideline or Policy in whole or in part. ${ }^{99}$ The only two states that have yet to adopt any pain re-

93. Id.

94. Id. (2007).

95. Scott M. Fishman, Responsible Opioid Prescribing: A Physicians Guide

96. MODEL POLICY, supra note 71, at 2.

97. Id.

98. See Database of State Statutes, Regulations, and Other Official Governmental Policies, PAIN \& POLICY STUDIES GROUP, http://www.painpolicy.wisc.edu/matrix.htm (last visited Jan. 17, 2011).

99. Id. 
lated policy are Illinois and Indiana. ${ }^{100}$ While this Note does not formally endorse any specific guidelines or policy currently in existence, the Model Policy would be an excellent choice considering its wide range of endorsements and the ease at which the Board could adopt it.

\section{B. The Michigan Guideline}

The State of Michigan has taken an extensive approach to dealing with pain management and adopted Guidelines for the Use of Controlled Substances for the Treatment of Pain ("Guidelines") in late 2003. ${ }^{101}$ In addition to the Guidelines, Michigan has adopted similar guidelines for nurses and pharmacists, maintains a website dedicated to pain management, sends a quarterly pain management newsletter to all licensed physicians, has distributed 70,000 copies of Dr. Scott Fishman's prescribing guide, and surveys licensed physicians on multiple areas including pain management practices. ${ }^{102}$ Suffice it to say, pain management is a priority in Michigan.

While Michigan is achieving many positive results in the area of pain management, its clear and unambiguous law is arguably the most important aspect of its pain management policies. Michigan's Guidelines are virtually identical to the Model Policy, including the Preamble and Definitions. ${ }^{103}$ Further, Michigan's pain management policies and law received an A grade from the Wisconsin Pain and Policy Studies Group ("PPSG"). ${ }^{104}$ The PPSG grades every state on the balance and clearness of its pain management laws, regulations, and other regulatory policies. ${ }^{105}$ The grade is based on provisions that enhance pain management versus the provisions that hinder pain management, and a grade of A is only possible when a state's relevant policies completely eschew restrictive or ambiguous language. ${ }^{106}$ For example, the Michigan Guidelines state, "[p]hysicians should not fear disciplinary action from the Board or other state regulatory or enforcement agency for prescribing, dispensing or administering controlled substances, including opioid analgesics, for a legitimate medical purpose and in the

100. Id.

101. Id.

102. Bureau of Health Professions Launches Pain Management Newsletter, MIPaINMGMT. (Mich. Dept. of Community Health, Lansing, Mich.), Fall 2010, at 1-2, available at http://www.michigan.gov/documents/mdch/MIpain_Management_330 510_7.pdf.

103. Michigan Guidelines for the Use of Controlled Substances for the Treatment of Pain, MICH. BD. OF MED. (2003), available at http://www.michigan.gov/documents/ mdch_MI_guidelines_91795_7.pdf.

104. Pain \& Policy Studies Group, achieving Balance in Federal and State Policy: A Progress Report Card 11 (4th ed. 2008) [hereinafter A Progress RePORT CARD].

105. See Pain \& Policy Studies Group, Achieving Balance in Federal and State Policy: A Guide to Evaluation (5th ed. 2008) [hereinafter A Guide to Evaluation].

106. A PROGRESS REPORT CARD, supra note 104, at 25. 
usual course of professional practice." ${ }^{107}$ Under the PPSG evaluation, this provision enhances pain management because it directly addresses physicians' fear of regulatory scrutiny. ${ }^{108}$ In contrast, an Indiana Pharmacy regulation states, "[a] prescription for a controlled substance to be effective must be issued for a legitimate medical purpose in a reasonable quantity by an individual practitioner acting in the usual course of his professional practice." 109 The PPSG deemed this provision as potentially impeding pain management because it is ambiguous and sets an arbitrary standard for legitimate prescribing. ${ }^{110}$

Because Michigan received thirty-seven positive provisions and zero negative provisions, the PPSG graded Michigan with an A, one of only five states to receive the grade. ${ }^{111}$ Indiana received a C-plus grade because its policies and law contain only six positive and two restrictive or ambiguous provisions, including the one noted previously. ${ }^{112}$ Michigan has abundant positive provisions and clearly promotes the safe and effective use of controlled substances for pain management, while Indiana has very few provisions, positive or negative, that relate to pain management and controlled substances. ${ }^{113}$

In addition to Michigan's positive report with the PPSG, they conducted a survey in 2009 for the first time on pain management practices in Michigan. ${ }^{114}$ The survey included information on physician attitudes towards chronic pain treatment, physician pain management education, and reasons why physicians are reluctant to prescribe opioids. ${ }^{115}$ The most interesting discovery was that when asked to define the greatest barrier to addressing pain, thirty-two percent of respondents answered that they were afraid their patients would become addicted to opioids, and only five percent stated it was fear of regulatory scrutiny. ${ }^{116}$ Considering all of the literature and reports that cite fear of regulatory scrutiny as a primary barrier to proper pain treatment, it was the sixth of seven reasons stated as the cause of inadequate pain treatment in Michigan. ${ }^{117}$ While Michigan respondents were not asked why they felt this way, one can reasonably conclude that the clarity of the law in Michigan has significantly lowered its physicians' con-

107. MICH. BD. OF MED., supra note 102.

108. A GUIDE TO EVAlUATION, supra note 105 , at 314.

109. 856 IND. ADMIN. CODE 2-6-3(a) (2010) (emphasis added).

110. A Guide to Evaluation, supra note 105, at 224.

111. Id. at 314.

112. A PROGRESS REPORT CARD, supra note 104, at 11.

113. As noted previously, Indiana has several provisions relating to controlled substances, however, those provisions do not involve prescribing practices.

114. Mich. Dep'T OF CMTy. Health, SuRVEY of Physicians (2009), available at http://www.michigan.gov/documents/healthcareworkforcecenter/2009PhysiciansSurveyFIN ALREPORT_308082_7.pdf.

115. Id. at 12-16.

116. Id. at 16.

117. Id. 
cern over regulatory scrutiny. This seems particularly sensible because the current theory is that clear and unambiguous pain treatment regulations will reduce physician concern. ${ }^{118}$ Thus, Michigan physicians feel (1) their patients will become addicted, (2) their patients fail to properly report pain, (3) lack of physician training and knowledge in pain management, (4) insufficient time to asses patient pain, and (5) lack of effective medicine are all greater barriers to adequate pain treatment than fear of investigation by authorities. ${ }^{119}$ As such, where fear of regulatory scrutiny is a minor barrier in Michigan, the Michigan Board of Medicine ("Michigan Board") has taken steps to better educate its physicians by maintaining a website dedicated to pain management and sending a quarterly pain management newsletter to all licensed physicians. It has also distributed 70,000 copies of Dr. Scott Fishman's prescribing guide.

Even though the Michigan Board has taken numerous steps to ensure that physicians have the tools to properly treat pain, its initial goal was to clarify the law on acceptable pain treatment. ${ }^{120}$ That was done largely through Michigan's adoption of the Guidelines for the use of controlled substances for pain treatment in guideline form, thus reducing physician fear of regulatory scrutiny.

\section{Indiana's Attempt to Promulgate a Rule for Using Controlled Substanc- es in a Pain Treatment Setting}

In 2006, the Board considered and came very close to adopting the Model Policy in almost its entirety. ${ }^{121}$ On June 1,2005 , the Board filed a Notice of Intent to begin the promulgation process on rules concerning pain management and controlled substances. ${ }^{122}$ In a letter to the Board, multiple Indiana physician organizations indicated that the reason for promulgation "was a reaction to requests made by physicians for clarification on the use of controlled substances for pain management." ${ }^{\text {"123 }}$ The Board drafted ${ }^{124}$ a

118. See Leelyn, supra note 71 , at 156 .

119. Mich. DeP'T OF CMTY. HeALTH, supra note 113, at 16.

120. The Michigan Board passed its Guidelines for the Use of Controlled Substances for the Treatment of Pain in 2003; this was before it began its other pain management initiatives. Fed'N State Med. Bds., Pain TReatment Policies, Legislation and Regulations: BOARD-BY-BOARD OVERVIEW 6 (2012), available at http://www.fsmb.org/pdf/GRPOL Pain_Management.pdf. See also Pain and Symptom Management, MiCH. DeP'T. OF LICENSING AND REGULATORY AFFAIRS, http://www.michigan.gov/mdch/0,1607,7-13227417 45947---,00.html (last visited Mar. 7, 2012).

121. Ind. Prof'l Licensing Agency, MLB Timeline For Pain Management Rule, Feb. 6, 2006 (on file with the Dir. of the Ind. Med. Licensing Bd.); see also 28 Ind. Reg. 3344 (Aug. 1, 2005).

122. Id.

123. Memorandum from Am. Coll. of Emergency Physicians, Ind. Chapter et al., to the Ind. Med. Licensing Bd., (Nov. 29, 2005) (on file with the Director of the Indiana Medical Licensing Board).

124. The proposed rule was drafted by the Board in conjunction with an AG advisory 
proposed rule that looked nearly identical to the Model Policy except it excluded the Preamble section, replacing every "should" with "shall" and essentially codifying in 844 IAC 5 a mandatory version of the Model Policy without the Preamble section. ${ }^{125}$ The reason for the mandatory standard was the Advisory Division of the AG, which counsels the Board on legal matters. ${ }^{126}$ The Advisory Division advised the Board that only a regulation should be promulgated to ensure enforceability. ${ }^{127}$ For example, the Model Policy states, "The medical record should document the nature and intensity of the pain, current and past treatments for pain, underlying or coexisting diseases or conditions, the effect of the pain on physical and psychological function, and history of substance abuse." ${ }^{, 128}$ The Indiana corollary stated,

The medical record shall document the following: (A) The nature and intensity of the pain. (B) Current and past treatments for pain. (C) Underlying or coexisting diseases or conditions. (D) The effect of the pain on physical and psychological function. (E) History of substance abuse. (F) The presence of one (1) or more recognized medical indications for the use of a controlled substance. ${ }^{129}$

The proposed rule was published in the Indiana Register on August 1 , $2005 .^{130}$ At the Board meeting on August 26, 2005, a representative from the Indiana State Medical Association ("ISMA") submitted a letter detailing suggested changes, 131 including changing "shall" back to "should."132 The reasoning underlying this suggested change was that "[ $t]$ he state purpose of the proposed rule is to establish guidelines. The use of 'shall' indicates a mandate or a limit and could potentially hinder a physician from tailoring treatment to the specific, varying needs of his/her patients."133

At the hearing, the Board discussed the concerns submitted by the ISMA and voted to adopt the proposed rule in its "shall" form by a unani-

attorney. IND. MED. LICENSING BD., MINUTES, Oct. 27, 2005 (on file with the Director of the Indiana Medical Licensing Board).

125. 28 Ind. Reg. 3344 (Aug. 1, 2005).

126. See IND. CODE § 4-22-2-22 (2010).

127. Interview with Mike Rinebold, Dir. of Gov't Relations, Ind. State Med. Ass'n (Mar. 7, 2011) (on file with author); Mr. Rinebold was the director of the Board during the 2005-06 rule promulgation process. IND. MED. LICENSING BD., MiNUTES, Apr. 28, 2005 (on file with the Director of the Indiana Medical Licensing Board).

128. 28 Ind. Reg. 3344 (Aug. 1, 2005) (emphasis added).

129. Id. (emphasis added).

130. 28 Ind. Reg. 3344 (Aug. 1, 2005).

131. There were several suggested changes: modify the definition of addiction, modify the definition of chronic pain, and change all instances of "Shall" to Should." Letter from Elizabeth Eichhorn to the Ind. Med. Licensing Bd. (Aug. 26, 2005) (on file with the Director of the Indiana Medical Licensing Board).

132. Id.

133. Id. 
mous vote. ${ }^{134}$ However, after the Board sent the proposed rule to the AG for approval on September 8, 2005, the Board received multiple letters of concern from physician organizations, including the Indiana Chapter of the American College of Emergency Physicians, Indiana Academy of Family Physicians, Indiana Academy of Ophthalmology, Indiana Osteopathic Society, Indiana Psychiatric Society, Indiana Society of Anesthesiologists, and the ISMA. In each of the letters, the primary concern was the mandatory nature of the proposed rule established by the use of "shall" throughout. 135 As a result of the large medical outcry, the Board voted to recall the rule on September 23, 2005, ${ }^{136}$ and it held an additional meeting on November 30 , 2005 to discuss these concerns. ${ }^{137}$ Although the meeting resulted in some consensus between Indiana medical organizations, the ISMA continued to oppose any standard in rule form and would only support a guideline form, arguing that a mandatory rule in this area would discourage and burden pain management rather than facilitate it. ${ }^{138}$ Without the support of the ISMA and others, the Board decided to abandon the rule promulgation on February $23,2006 .{ }^{139}$

\section{How a Guideline Would Operate Under Indiana's Statutory Scheme}

Considering the diversity of the fifty states in the United States, and the fact that policies and legislation regulating physician practice is primarily a state level function, every state is different in the way it investigates, prosecutes, and disciplines physician behavior. In Indiana, the Board may only discipline physicians who violate the Charging Statute. ${ }^{140}$ Specifically concerning physician prescribing, the Catch All statute, requires some other basis to show the physician failed to keep abreast of current professional

134. IND. MED. LiCENSING BD., Minutes, Aug. 26, 2005 (on file with the Director of the Indiana Medical Licensing Board).

135. See Letter from Elizabeth K. Cierziniak on behalf of the Ind. Soc'y of Anesthesiologists to the Ind. Med. Licensing Bd. (Sep. 22, 2005) (on file with the Director of the Indiana Medical Licensing Board); Memorandum from Am. Coll. of Emergency Physicians, supra note 122; Letter from Am. Coll. of Emergency Physicians, Ind. Chapter, et al, to the Ind. Med. Licensing Bd. (Oct. 25, 2005) (on file with the Director of the Indiana Medical Licensing Board); IND. PROF'L LICENSING AGENCY, MLB Timeline For PAIN MANAGEMENT RULE, Feb. 6, 2006 (on file with the Director of the Indiana Medical Licensing Board).

136. 29 Ind. Reg. 549 (Nov. 1, 2005).

137. Ind. Prof'l Licensing Agency, MLb Timeline For Pain Management Rule, Feb. 6, 2006 (on file with the Director of the Indiana Medical Licensing Board).

138. Letter from Kevin R. Burke, M.D., on behalf of the Ind. State Med. Ass'n to the Ind. Med. Licensing Bd. (Jan. 16, 2006) (on file with the Director of the Indiana Medical Licensing Board); IND. Prof'L Licensing AGEnCY, MLB TIMEline For PAIN MANAGEMENT RULE, Feb. 6, 2006 (on file with the Director of the Indiana Medical Licensing Board).

139. IND. MED. LICENSING BD., MINUTES, Feb. 23, 2006 (on file with the Director of the Indiana Medical Licensing Board).

140. IND. CODE § 25-1-9-9 (2010). 
theory and practice. ${ }^{141}$ A formally adopted guideline in this area would simply provide the basis for invoking the Catch All statute. For instance, the AG would charge the physician under the Catch All statute, citing the guideline and pointing to the specific deviation.

The most effective way for the Board to enforce and ensure affected physicians follow the guideline would be for the Board to codify a closely worded version of the Model Policy in 844 IAC 5, essentially completing the Board's attempt in 2006 with a few changes. Specifically, the Board should write the Model Policy into a rule under 844 IAC 5, leaving all the permissive characteristics, but where the Model Policy has a list of actions that physicians should adhere to, the Board should require that any deviation be documented in the record with a medical justification for the deviation. ${ }^{142}$ The Board's rule under 844 IAC 5 would be identical to the Model Policy but would read, "any deviation from this section shall be documented in the medical record with medical justification for the deviation." This addition to the Model Policy would add enough teeth to properly enforce the guideline, while also giving physicians enough flexibility to meet each patient's need. Such a guideline promulgated in rule form would directly address the concern by the Advisory division and the medical community because although physicians would be required to document any deviation, the deviation would not automatically require discipline but allow for flexibility and consideration by the Board.

Under a rule promulgated in this fashion, the Board would be forced to consider the guideline under 844 IAC 5 because physicians would be required to document and thus highlight any deviation. The Board could then properly evaluate physician conduct, and in the event of a deviation from the policy, the Board would retain discretion to discipline or accept the deviation as appropriate where the circumstances warrant. ${ }^{143}$ This would create a clear and unambiguous law concerning prescribing controlled substances for pain treatment, allow the AG to use an enforceable tool to prosecute inappropriate practices, and grant physicians a flexible standard to meet the varying needs of chronic pain patients.

\section{THE Role of A GUIDELINE TO ACHIEVE AND BALANCE ALl INTEREST}

Considering the interests stated previously and the positive impact

141. IND. CODE § 25-1-9-4(a)(4)(B) (2010).

142. See IND. CODE § 25-1-9-4(a)(4)(B) (2010).

143. For example, the Model Policy states that physicians should adhere to certain actions in their prescribing behavior and the Board will not discipline for deviation when reasonable medical justification is documented. Therefore, the Model Policy is a guide to prescribing rather than a rule and its codification in 844 IND. ADMIN. CODE 5 would not alter the guide-like nature of the Model Policy. Rather, adoption would simply require the Board to consider it and only impose one rule-like provision: documentation in instances of deviation. See MODEL POLICY, supra note 71. 
Michigan's Guideline is having in reducing fear of regulatory scrutiny, the Board should adopt a guideline for the use of controlled substances for the treatment of pain. Such a guideline will serve two direct and beneficial purposes by (1) providing the AG and the Board with a standard under which to evaluate physician prescribing practices, thus facilitating prosecution and discipline for those who use medicine as a pretext for diversion, and (2) clarifying the law and the Board's position in using controlled substances for pain treatment, which will help reduce physician fear of regulatory scrutiny and will facilitate the provision for proper treatment of patients with unremitting pain.

\section{A. A Guideline Will Clarify the Law and Create Case Evaluation Criteria}

The Board should adopt a guideline based on a widely accepted standard of practice for physicians who prescribe controlled substances for pain treatment, such as the FSMB's Model Policy of 2004. Such a formally adopted or codified guideline will provide the Board with a foundational source for what has been determined to be proper standards of conduct. Rather than hearing arguments and relying on standards from other states, federal agencies, or private organizations, the Board would have its own resource to make such hearings more efficient and consistent. The current state of unclear and nonexistent laws or guidelines is unacceptable and detrimental to medical care. A guideline that represents the Board's expectations and establishes case evaluation criteria would define what unprofessional conduct looks like in a pain management setting. ${ }^{144}$ This need is heightened by the fact that some standard of care concerning using controlled substances for pain treatment has been adopted in every state save for Indiana and Illinois.

\section{The Indiana Medical Licensing Board Members Are Not Pain Manage- ment Specialists}

One of the major reasons for formally adopting standards of practice for pain treatment or any specialized area of medicine is that Board members are not experts in every area of medicine. Moreover, currently no pain management specialists serve on the Board. ${ }^{145}$ A study completed by Diane E. Hoffmann and Anita J. Tarzian revealed that numerous state medical board members believed their adoption of a guideline or policy was "a sig-

144. See Stark, supra note 14, at 612-13; see also Leelyn, supra note 71, at 153 ("All states must adopt model guidelines, and medical board members, because of their vast power over health care practitioners, must internalize the model provisions and policies, and scrupulously apply them in evaluating physicians' prescription practices.").

145. List Of Medical Licensing Board Members, IND. Prof'L LICENSING AgENCY, available at $\mathrm{http}: / \mathrm{www} . \mathrm{in} . \mathrm{gov} / \mathrm{pla} / 2485 . \mathrm{htm}$ (last updated Apr. 2011). 
nificant aid to them in deciding whether to investigate or discipline a physician."146 Further, when asked what factors their board would use to evaluate prescribing practices, "most respondents stated that it was a matter of judgment, that it was very fact specific, and often subjective."147 "However, for those that had established pain management policies or guidelines, these appeared key in determining whether to discipline. Significant departures from the policies, in some cases, could be a basis for discipline." Moreover, a survey conducted by Dr. Aaron Gilson, Senior Researcher for the PPSG, discovered that seventy-five percent of state medical board members felt it was very important for their state "to have a policy (i.e., regulation, guideline, or policy statement) for licensees regarding pain management and controlled substances."149 This statement is further evidenced by the fact that forty-nine of fifty-one U.S. jurisdictions have adopted some form of statement in either their law or adopted policy. ${ }^{150}$ Even more concerning was the revelation of Dr. Gilson's survey that many board members held misconceptions about clinical issues. For example, only forty-three percent of board members surveyed were aware that federal law had no limits on the amount a physician can prescribe at one time, and twenty-seven percent "either did not know or incorrectly thought that physicians could not legally prescribe methadone for chronic pain."

Medicine is a wide and diverse discipline, much like the practice of law. Simply because someone is an attorney does not mean he is an expert or is even knowledgeable about every area of the law. A wills and trusts attorney would likely be lost in a criminal proceeding involving a homicide. Similarly, Board members who are physicians may not know the proper methods of pain management, and even if there is one, Board membership changes with every new appointee. Such is the critical need for some guideline to assist the Board in evaluating physician prescribing practices.

\section{The Case of David and Charles Chube}

Where prescribing controlled substances for pain is a legally complex

146. Hoffmann \& Tarzian, supra note 67 , at 36.

147. Id. at 37.

148. Id.

149. Aaron Gilson, State Medical Board Members' Attitudes About the Legality of Chronic Prescribing to Patients with Noncancer Pain: The Influence of Knowledge and Beliefs About Pain Management, Addiction, and Opioid Prescribing, 40 J. PAIN \& SYMPTOM MGMT. 599, 603-04 (2010).

150. Database of State Statutes, Regulations, and Other Official Governmental Policies, PAIN \& POL'Y STUDIES GRP. (Dec. 7, 2011), http://www.painpolicy.wisc.edu/matrix.htm (last visited Jan. 17, 2011).

151. Gilson, supra note 148, at 604 ; see also Leelyn, supra note 71 , at 142 ("Fifty percent of medical board members surveyed erroneously believed prescribing schedule II drugs violates the law, contrasted with only twelve percent who correctly understood that physicians may lawfully prescribe opioids to patients with chronic, non-malignant pain."). 
and medically subjective area, it is evident that the Board is in need of some guideline to follow in making decisions on discipline and on general evaluation of physician prescribing practices. To illustrate this point, consider the case of Drs. David and Charles Chube, who are currently serving federal prison sentences for their inappropriate prescribing practices. ${ }^{152}$ Doctors David and Charles Chube are brothers who operated multiple family clinics in Munster and Gary, Indiana, where they frequently treated chronic pain patients using controlled substances. ${ }^{153}$ In 2001, a patient of the Chubes who had been treated with Oxycontin was arrested and charged with knowingly and intentionally distributing Oxycontin pills. ${ }^{154}$ In return for a reduced sentence, the patient agreed to identify his "suppliers" and testify against them, leading DEA officials to the Chubes. ${ }^{155}$ The Chubes denied all wrongdoing and argued that they had in good faith prescribed controlled substances for legitimate medical reasons. ${ }^{156}$ At trial, the government presented ninety-eight patient files, all of which were examined by two expert witnesses who both testified that the doctors' prescribing practices were not for legitimate medical purposes. ${ }^{157}$ Further, four of the Chubes' patients testified that they lied about their pain solely to obtain the drugs. ${ }^{158}$

Although the Chubes and the government presented radically different accounts of the prescribing practices, from trying to serve the public and reduce pain to "pill pushers," the jury found David Chube guilty of four counts of unlawful distribution and two counts of health care fraud and Charles Chube guilty of one count of unlawful distribution. ${ }^{159}$ The most relevant part of this case for the purposes of this Note is not what transpired in federal court but rather the actions of the Board that occurred under the same set of facts. On April 25, 2005, the AG filed a Petition for Summary Suspension, which would have placed the Chubes' Indiana medical licenses on emergency suspension for ninety days, arguing that the Chubes posed an immediate threat to the public safety and welfare. ${ }^{160}$ As evidence for the petition, ${ }^{161}$ the AG not only looked to the DEA reports but also inde-

152. See Don Terry, How Two Respected Gary Physicians Wound Up Doing a Combined 20 Years in Federal Prison, CHI. TRIB., Aug. 31, 2008, Magazine, at 8, available at 2008 WLNR 16463427; United States v. Chube, 538 F.3d 693 (7th Cir. 2008).

153. United States v. Chube, 538 F.3d 693, 695 (7th Cir. 2008).

154. Id.

155. Id.

156. Id.

157. Id. at 697.

158. Id. at 696.

159. Id.

160. Petition for Summary Suspension, Indiana v. Charles R. Chube, 2005 MLB 0023 (Ind. Med. Licensing Bd., Apr. 25, 2005) [hereinafter Charles Chube, Petition for Summary Suspension]; Petition for Summary Suspension, Indiana v. David D. Chube II, 2005 MLB 0024 (Ind. Med. Licensing Bd., Apr. 25, 2005).

161. The petitions for both Chubes filed by the AG are identical; therefore, all material referencing both petitions will be cited to Charles Chube's petition. 
pendently reviewed the patient medical records and concluded that the Chubes had prescribed multiple patients "[s]chedule II and [s]chedule III drugs with no documentation of medical history, physical examination, diagnosis or treatment plans." ${ }^{162}$ Essentially, the AG argued that the Chube brothers violated the Catch All statute because they failed to adhere to generally accepted standards of medical record keeping when prescribing controlled substances. ${ }^{163}$

What may have appeared to be a clear case for summary suspension actually resulted in the Board denying the AG's petition. ${ }^{164}$ Then Board President Dr. Bharat Barai stated in a subsequent interview that "[t]he charts that were reviewed at random did not find anything wrong . . . Patients were referred to pain centers when appropriate."165 When the AG filed the formal complaint, the brothers were charged with violations of, among other things, the Catch All statute, to wit 844 IAC 5-2-5, which requires practitioners to follow "generally accepted scientific principles, methods, [and] treatments."166 "The brothers later agreed to indefinite suspension pending their federal appeal. ${ }^{167}$ While the AG found evidence that the brothers had no documentation of medical history, physical examination, diagnosis, or treatment plans, the Board did not find them to be an immediate danger to the public. Even though the standard for a summary suspension is higher than in a regular hearing on the merits, ${ }^{168}$ the AG pointed to specific instances of failure to prescribe in a certain way, which were clear deviations from the Model Policy. ${ }^{169}$ Without any reference to how physicians should prescribe controlled substances, the Board President simply concluded that the randomly reviewed charts revealed nothing wrong. ${ }^{170}$ Yet, the Chubes' conduct was measured simply against the impressions of the Board members, who were not pain management special-

162. Charles Chube, Petition for Summary Suspension, supra note 160, at 2.

163. There is no indication of what specific standard the AG referred to in support if its petition, but it can be assumed that he was relying on 844 IAC 5-2-5, which requires practitioners to follow "generally accepted scientific principles, methods, [and] treatments," based on the charges in the subsequently filed compliant. See Complaint at 3, Indiana v. Charles R. Chube, 2005 MLB 0023 (Ind. Med. Licensing Bd., Jun. 28, 2006); Complaint at 4, Indiana v. David D. Chube II, 2005 MLB 0024 (Ind. Med. Licensing Bd., Jun. 28, 2006).

164. Order Denying Petition for Summary Suspension, Indiana v. Charles R. Chube, 2005 MLB 0023 (Ind. Med. Licensing Bd., Jun. 2, 2005); Correction of Order Denying Petition for Summary Suspension, Indiana v. David D. Chube II, 2005 MLB 0024 (Ind. Med. Licensing Bd., Oct. 6, 2005).

165. See Terry, supra note 151 , at 8 .

166. 844 IND. ADMIN. CODE 5-2-5 (2010).

167. See Indefinite Summary Suspension Order, Indiana v. Charles R. Chube, 2005 MLB 0023 (Ind. Med. Licensing Bd., Jan. 31, 2007); Indefinite Summary Suspension Order, Indiana v. David D. Chube II, 2005 MLB 0024 (Ind. Med. Licensing Bd., Jan. 31, 2007).

168. See IND. CODE $\S 25-1-9-10$ (2010).

169. Charles Chube, Petition for Summary Suspension, supra note 160, at 1-2.

170. Id. 
ists. $^{171}$

This Note does not suggest that the Chubes were "common drug dealers" as alleged by the federal government, ${ }^{172}$ but it is clear they were not taking appropriate precautions in prescribing Oxycontin. Physicians cannot prevent patients from lying to them; however, they also cannot prescribe every new patient Oxycontin when the patient claims he is in extreme pain, especially when Indiana and the United States are experiencing an epidemic in prescription drug abuse. The AG specifically pointed to the flaws in the brothers' practice, all of which are covered by the Model Policy, and the Board unanimously rejected them because they did not "feel comfortable suspending [the Chubes'] licenses."173 Because the Board did not have any reference or framework as to what were appropriate prescribing practices, it allowed two potentially honest, but careless physicians to retain their licenses. With a guideline, the Board could have easily seen and addressed the deviation, potentially changing the outcome of their determination. ${ }^{174}$

The Chube brothers case illustrates that, without a policy outlining standards of practice, the AG is left to argue under the theory of generally accepted medical principles, and the Board has no real way to evaluate borderline prescribing practices. ${ }^{175}$ The Chubes were not linked to any overdose deaths; they kept some semblance of a medical records; and, they did not prescribe to family members. ${ }^{176}$ Commenting on the Chubes' federal trial and Board hearing, Dr. Rollin M. Gallagher, then president-elect of the American Academy of Pain Medicine, stated the problem was that "there are not clear standards for prosecutors to follow, just like there are not clear guidelines for physicians to follow in easing pain." 177 This is the heart of the interest for the Board and the AG. Clear standards to prosecute and evaluate are not available. Such is a disservice to the AG, the Board members, and the Chubes, who might not have known what a medical record should contain to help prevent diversion and abuse.

171. The participating Board members for the Chube hearing were Richard Krejsa, D.O. (geriatric medicine and family practice), Stacy Lankford, M.D. (urology), Bharat Barai, M.D. (hematology and oncology), Ralph Stewart. M.D. (ophthalmology), William Beeson, M.D. (otolaryngology and cosmetic surgery), Ms. Barbara Malone (consumer member). IND. MED. LiCENSING BD., MinUTES 17 (Apr. 28, 2005).

172. United States v. Chube, 538 F.3d 693, 696 (7th Cir. 2008).

173. IND. MED. LiCENSING BD., MinUTES (Apr. 28, 2005).

174. See Hoffmann \& Tarzian, supra note 67, at 17 (A surveyed board member explained, "we have pain management guidelines that we've published, and it's easy to compare a physician's behavior to those guidelines, but I'd say we refer to a pain management expert in about 20 percent of the investigations, but they [also] use our guidelines.").

175. See Hoffmann \& Tarzian, supra note 67, at 12 (Surveyed Medical Board members explicated, "the board's attitude has changed; now we have pain management guidelines and have an established way of determining if a physician is deviating from those guidelines. We're more aware of the need for adequate pain management and how that should be documented.").

176. See United States v. Chube, 538 F.3d 693.

177. Terry, supra note 151. 
B. Clear Standards Put Physicians on Notice as to Proper Prescribing Practices

In addition to a guideline providing an evaluation and prosecution tool for the Board and the AG, a clear standard would communicate to physicians what is expected of them when it comes to prescribing opioids for pain treatment. The ability of physicians to know the Board's expectations serves two different needs: (1) so the physician may prescribe without fear of state investigation, and (2) so that when there is an investigation, the physician may adequately defend himself.

\section{A Guideline Will Alleviate Fear of Regulatory Scrutiny}

When physicians are aware that their state medical board has a clear and published standard of practice, their concerns about state investigation will likely recede because they will know what the state expects them to do. As noted in the 2009 Michigan survey, Michigan physicians report that they do not fear regulatory scrutiny, which is directly related, at least in part, to the fact that Michigan has clear policies and law on prescribing controlled substances for pain treatment. ${ }^{178}$ The Model Policy was developed to "clarify the Board's position on pain control, particularly as related to the use of controlled substances, to alleviate physician uncertainty and to encourage better pain management."179

Physicians who face investigation and charges will potentially pay a high price regardless of whether discipline is handed down, including financial costs, damage to reputation, loss of business, and other consequences. ${ }^{180}$ Physicians are aware of the costs, and in an effort to avoid investigation and charges, many will alter their prescribing or avoid certain types of patients completely. ${ }^{181}$ A guideline, especially when coupled with broad dissemination and communication activities from the Board, can alleviate the tension between physicians and the fear that their prescribing practices will lead to damaging scrutiny. If the guideline states that the medical chart should contain a medical history, patient examination, and a medical reason for the prescription, then the physician will know what the Board and the AG will be looking for in a chart should a patient complain. Further, if one of the provisions is not practical or possible for the specific patient, the physician will be aware of his deviation from the guideline and can document the reasons for such deviation. Without knowing the evaluation criteria used by the Board, physicians will continue to undertreat pain

178. Mich. DEP'T OF CMTY. HeAlTH, supra note 113, at 16.

179. MODEL POLICY, supra note 71.

180. Johnson, supra note 65, at 1029.

181. Id. at 1030 . 
and refrain from subjecting themselves to unwarranted investigation. ${ }^{182}$ When physicians have a published guide from the Board, they can practice without fear because they will know the parameters of acceptable prescribing actions and will have a set of expectations with which they can comply. This is the core of barriers to adequate pain management, which the Board has the direct and sole ability to address and alleviate. ${ }^{183}$

\section{A Clear Guide Will Enable Proper Defense}

In addition to alleviating fear of regulatory scrutiny, a guideline will give physicians a clear standard they can use to defend their practices. Without a clear standard, physicians are unable to adequately defend themselves because there is no clear means under which to defend their actions. They are left to justify their prescribing behaviors under a standard of generally accepted practice, as is the AG. While the AG is in the same position from an evidentiary perspective, the common outcome is for the physician to settle.

On October 30, 2009, the AG filed a complaint against the license of Dr. Michael Punnett. ${ }^{184}$ From March 2007 through November 2008, Dr. Punnett treated a patient for pain using different medication including Percocet, a schedule II controlled substance, Lortab, and Norco, both schedule III controlled substances. ${ }^{185}$ Throughout the course of the treatment, the patient would ask for increased doses, decreased doses, early refills, and new medication because the medication had either been lost, stolen, or flushed by his wife. ${ }^{186}$ On numerous occasions, Dr. Punnett rejected the patient's request for early refills or refused to prescribe anything more until the patient underwent another physical exam. ${ }^{187}$ However, Dr. Punnett did prescribe different doses of medication at the patient's request several times-including when he claimed that he had lost his medication with his luggage, or that his wife had flushed them down the toilet ${ }^{188}$ In April 2008, Dr. Punnett noted in the patient's medical chart that the patient needed to be seen because of suspicious refill requests. Dr. Punnet examined the patient the next day, but there was nothing documented in the med-

182. Shannan W. Leelyn, Failures in Pain Management: The Collision of Law and Medicine, 27 T. JEFFERSON L. REv. 133, 154 (2004) (stating "[u]ntil [a] line is drawn and physicians are able to understand the limitations imposed on them by law, physicians will continue to under-treat chronic pain").

183. Gilson et al., supra note 15 , at 119.

184. Complaint, In the Matter of the License of Michael A. Punnett, 2009 MLB 0032 (Ind. Med. Licensing Bd., Oct. 30, 2009).

185. Id.

186. Id.

187. Id.

188. Id. 
ical record as to what was discussed. ${ }^{189}$ After being notified by the patient's wife that the patient was lying about losing his medication, Dr. Punnett conducted a follow-up examination and discovered that the patient was taking eight to ten Hydrocodone a day and had been admitted to a behavioral health program. ${ }^{190}$ During the meeting, Dr. Punnett noted in the medical chart that opioids should not be given and the patient should potentially be discharged from the practice. ${ }^{191}$ However, Dr. Punnett prescribed one last dose of Norco for the patient, and there was no mention in the medical chart as to a reason. ${ }^{192}$

The AG charged Dr. Punnett with multiple violations of prescribing to a known addict, failure to keep abreast of current theory or practice, and failure to take proper precaution to identify and address the patient's addiction. ${ }^{193}$ Rather than take his chances with the Board, Dr. Punnett settled and simply received a Letter of Reprimand from the Board. ${ }^{194}$ Had this case been presented before the Board, the outcome is speculative at best. Dr. Punnett did recognize that there were potential problems with the patient and brought him in for examination. However, he continued to prescribe for pain for reasons unknown. Pain management is a tricky and extremely subjective practice. ${ }^{195}$ Maybe the patient really was in extreme pain, or maybe the patient, when he confessed he had a problem and was in a rehab program, truly needed the prescription in the medical judgment of Dr. Punnett. The point is, Dr. Punnett chose not to defend and place himself at the mercy of the Board. In the end, he settled for a potentially lesser discipline and walked away. Had there been some guidelines as to what the Board considered appropriate practice, Dr. Punnett would have been able to properly defend his practice and fight the charge before the Board. While a letter of reprimand does not technically restrict his ability to practice, it is public record, and other physicians may think twice before referring patients to him-in fearing that they might be implicated should something worse surface in the future.

The Punnett case illustrates the inability of physicians to adequately defend themselves and the propensity of a physician to settle rather than defend. This is an issue for the AG as well but presents a greater disadvantage to physicians because physicians stand to lose much more from an unfavorable outcome than does the AG. A guideline setting out evaluation

189. Id.

190. Id.

191. Id.

192. Id.

193. Id.

194. Stipulated Findings of Fact, Stipulated Conclusions of Law, Ultimate Conclusions of Law, and Order, In the Matter of the License of Michael A. Punnett, 2009 MLB 0032 (Ind. Med. Licensing Bd., June 30, 2010).

195. Jeffrey Wishik, Chronic Pain: Medical and Legal Aspects, 53 R.I. B. J. 23 (2004) (discussing the subjective nature of pain and ways to treat it appropriately). 
criteria would enable the physician to better evaluate his status under the guideline and thereby avoid an unwanted settlement because he could potentially present his case before the Board with the confidence and the knowledge that he followed the Board's expectations. Had there been a guideline, Dr. Punnett may have made a special notation as to his medical reasons for prescribing Norco to the patient after he discovered there were problems. Without a standard, many cases are too unclear, causing physicians to settle since at least then they have some control over the outcome. $^{196}$

\section{The Patients Will Receive Better Treatment}

When physicians do not fear regulatory scrutiny and can properly defend complaints, patients with chronic pain ultimately are the beneficiaries. Patients will now have more confident doctors who can not only aggressively and effectively but also responsibly and safely treat their pain. Moreover, the general public benefits from more effective and consistent treatment by physicians prescribing controlled substances for pain treatment because good doctors are duly recognized, and those who contribute to prescription drug abuse are more easily identified and successfully disciplined.

\section{The Case Against a Guideline}

In spite of all the benefits to be gained by adopting a guideline for the use of controlled substances for pain treatment, there are those who disapprove of the proposal for various reasons. However, despite the arguments, a guideline with an enforceability mechanism is in the best interest for all concerned.

\section{A. There is No Enforceability With a Guideline}

The argument against a guideline as advocated by the AG's Advisory Division is that a guideline lacks teeth or enforceability and ultimately will be useless, or even more problematic and confusing to implement. Only statutes and regulations which are promulgated by the Board can be enforced, and a guideline would give a false sense of enforceability, ultimately meaning nothing when the Board actually contemplates discipline for physician conduct. It is important to note that the Board would not discipline under the guideline, but rather, it would discipline under the Catch All statute citing the guideline as evidence of the physicians' inappropriate

196. Hoffmann \& Tarzian, supra note 67 , at 36 ("[Standards] serve to reassure physicians that they will not be disciplined for overprescribing opioids to patients with chronic pain if they conform to standards of practice and state pain policies."). 
practices without proper documented justification. In essence, the guideline would take the place of "generally accepted standards of practice."

This argument is the main reason for the Board's failed attempt in 2005 and 2006 to adopt a standard because the Board and the AG wanted a mandatory regulation, and physician organizations wanted a guideline. The drafters of the proposed rule, including an AG Advisory Division attorney, changed all of the "shoulds" to "shalls" to create an inflexible practice standard with the force of law. The Indiana medical associations completely opposed this effort, claiming that a hard and fast rule in the area of pain management would restrict medical decision-making and ultimately impair patient pain care. ${ }^{197}$ The medical associations argued that certain physicians, such as emergency department physicians who use opioids, would fall under the requirements of the proposed rule and would technically be in violation when they did not complete a full medical history or devise a treatment plan. ${ }^{198}$

Despite the Advisory Division's enforceability concern, the proposed solution that the Board should codify a version of the Model Policy with a requirement for documented deviation, gives the standard teeth to enforce because physicians would be required to follow the guideline or document reasons for deviation. That way, the Board would be in a position to evaluate the practices against the guideline and decide whether to accept justifications for deviation as legitimate. This solution creates a mandatory provision with maximum flexibility for physicians to treat pain. As such, medical organizations should accept the permissive nature of this scheme, and those concerned with being able to enforce the standard will have the means to require compliance or documented deviation by physicians.

However, even if the Board rejects the proposed scheme and adopted a guideline similar to the FSMB's Model Policy, the PPSG has stated, "while guidelines do not have binding legal force, they may help those regulated by an agency to better understand the regulating agency's standards of practice." 199 Both the Indiana medical associations and the PPSG's concern is further substantiated by the following statement:

Doctors are asking for reassurance, not more rules or laws. Even the best intentioned of them [laws and rules], create only more fears in the minds of doctors trying to do their best, and place more ammunition in the hands of lawyers and regulators! Doctors will avoid the treatment of pain, so as not to take the

197. See Letter from Kevin R. Burke, M.D. on behalf of the Ind. State Med. Ass'n. to the Ind. Med. Licensing Bd. (Jan. 16, 2006) (on file with the Dir. of the Ind. Med. Licensing Bd.).

198. Letter from Am. Coll. of Emer. Physicians, supra note 134.

199. A GUIDE TO EvaluATION, supra note 105 , at $\S 2$. 
chance of "not being in compliance" with some minor detail. $^{200}$

If the Board formally adopts a guideline, they are likely to use it when evaluating physician conduct as if it were binding because it has the Board's recognition as a standard of practice. Representatives of other medical boards that have guidelines or some other standard of practice have stated:

[I]f we don't have good documentation, if it doesn't appear that the physician's following the board's guidelines with respect to prescribing for pain, then we'll investigate... for the most part we adhere to [our pain guidelines]. . . [we've made] a lot of progress. . . .We set the minimum standard of care in any state, documentation, informed consent, proper referral, etc., so we look for that . . . the general policy that was made known to physicians is that we leave prescribing and pain management control issues to their professional judgment, but if there is a complaint, they better have proper documentation, such as informed consent, history and physical, monitoring, etc. $^{201}$

A purely mandatory regulation simply should not be passed in such a subjective area. The Board must retain some discretion to evaluate physician conduct because the goal is not to discourage physician conduct, but to encourage it without the restrictions inherent in mandatory standards. Moreover, if the Board were to adopt the Model Policy or some variation, it would likely only be a matter of time before Indiana medical associations also adopted the guideline as a clinical standard of practice for the profession. Thus, physician deviation, especially absent documented justification, could also become subject to medical malpractice in civil cases. ${ }^{202}$ In other words, Board members are likely to use it to enforce the charging statute,

200. Johnson, supra note 65 , at 1016.

201. Diane E. Hoffmann \& Anita J. Tarzian, Achieving the Right Balance in Oversight of Physician Opioid Prescribing for Pain: The Role of State Medical Boards, 31 J.L. MED. \& ETHICs 21, 10 (2003).

202. It is possible that when the Board adopts or codifies a guideline or policy for prescribing practices for pain management, other medical associations may do the same as a result of the Boards initial adoption. This is especially true of the Model Policy because the ISMA has already given it support, and where such a policy becomes a standard of practice in the medical profession rather than just for the license purposes, an unjustified violation would become subject to civil liability. See Memorandum from Am. Coll. of Emer. Physicians, supra note 122 . 
and physicians are likely to follow it, particularly when it is considered a standard of practice for the profession. Though the proposed solution best meets the enforceability concern, a formally adopted guideline will also garner compliance by the Board and medical community. That is all the enforceability that is needed.

\section{B. Restricts the Practice of Medicine}

In any case that a new law or guideline is developed, it will be argued that the practice of medicine will be restricted. This is true, and a guideline will restrict pain management to some degree because physicians will not have unfettered discretion to treat as they see fit. "Pain management physicians are restricted by these guidelines that the medical specialists claim do not make sense medically and impede the proper treatment of patients' needs regarding pain.,203

However, the degree that it is restricted is only to the extent that the physician has a plan of action, keeps good documentation, and prescribes responsibly. Dr. Punnett would not be allowed to prescribe to a potential addict without clear documentation as to why, and the Chube brothers would have been forced to take better precautions to prevent diversion and abuse. While this may be considered restrictive, it is minimal at worst and necessary to advance societal goals in preventing prescription drug abuse. Further, the whole purpose here is that any deviation is a clear deviation from accepted standards, and the guideline will not automatically impose judgment as a rule would, but would instead allow for deviation where good cause is documented. So, if Dr. Punnett prescribed after he knew of his patient's abuse problems, he could document that the patient needed the medication to survive his pain through the night and could argue that before the Board.

A goal that is reinforced by a guideline is to hold physicians accountable for their practices. The guideline looks for documentation, treatment plans, informed consent, and other items that accomplish accountability. As said before, deviation is allowable with documented justification, and the Board still retains discretion to adjudicate subjective physician conduct. Moreover, a formally adopted guideline is malleable and can be changed without the rigors of the rule-making process. When medical standards evolve, the guideline can be modified. This solution avoids unintended consequences because ambiguous standards and archaic requirements can be remedied more easily than a statute or regulation. Even though the proposed solution of codifying a version of the Model Policy does not strictly

203. Bhavani S. Reddy, The Epidemic Of Unrelieved Pain: The Ethical, Societal, and Regulatory Barriers Facing Opioid Prescribing Physicians, 27 J. LEGAL MED. 427, 438 (2006). 
fall under this malleability benefit, its requirement for documented justification is malleable to the point that the justification can reflect new legitimate advances in pain management practices.

\section{Specific Standards Are Not Necessary to Achieve Physician Discipline}

Substandard care in prescribing practices to treat pain with controlled substances is currently established in Indiana without guidelines. The AG was able to successfully prosecute Dr. Edwards, Dr. Foley, and others in the past year without guidelines. While that is true, as explained before, the physicians disciplined are either obviously prescribing with substandard care or are violating another specific provision. Further, in borderline cases such as those of the Chube brothers and Dr. Punnett, the AG had to rely on a settlement or an agreed order. The concern is whether the discipline will be as accurate, efficient, or consistent as it would be with a clear standard, and whether the AG is able to prosecute borderline cases, including those who are diverting with medicine as a pretext. Whether or not a guideline is necessary, it would undoubtedly make the AG's job easier and more efficient to be able to point to specific deviations from a policy than to argue the physician deviated from generally accepted standards of practice.

\section{Patient Concern of Required Documentation}

In some instances, patients become uncomfortable with restrictions and guidelines under which their doctors require compliance contracts in controlled substance settings. ${ }^{204}$ Patients feel they are not being trusted and are given an undesirable ultimatum to strictly comply or be dropped by their physician. ${ }^{205}$ While this is a complex clinical issue beyond the scope of this Note, society's problem with prescription drug abuse is an epidemic in our country. Although this concern is legitimate and should be handled with delicacy by the physician, it is not a sufficient enough concern to outweigh the benefits to patient care achieved by a guideline.

\section{CONCLUSION}

The Board has a duty to protect the citizens of Indiana, both from inadequate pain management and from diversion and abuse of controlled substances. Adopting or codifying a guideline would create a standard by which physician conduct could be evaluated and properly disciplined. A guideline also would help alleviate a major barrier to effective pain man-

204. Kevin B. O'Reilly, Pain contracts can undermine patient trust, critics say, AMEDNEWS.COM (Dec. 27, 2010), http://www.ama-assn.org/amednews/2010/12/27/ prsb1227.htm.

205. Id. 
agement and allow the Board to closely evaluate physician practice, which accomplishes both the interests in protecting patients and the public at large. The Board is the only entity in Indiana with the authority to adopt a guideline and should do so not only because it is its duty, but also to accomplish the valuable clinical and regulatory objectives that a guideline is intended to address. 